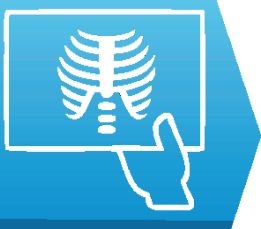

MEDICAL IMAGING

\title{
Ultrasound and magnetic resonance imaging evaluation of the femoral and sciatic nerves. A study of healthy volunteers
}

Georgeta Mihaela Rusuㄹ, Andra Diana Curcean ${ }^{1}$, Sorin Marian Dudea ${ }^{1,2}$

1) Radiology Department, Academic Emergency County Hospital, ClujNapoca, Romania

2) Radiology Department, Iuliu Hatieganu University of Medicine and Pharmacy, Cluj-Napoca, Romania
DOI: $10.15386 / \mathrm{mpr}-1629$

Manuscript received: 16.03 .2020

Received in revised form: 05.05 .2020

Accepted: 31.05.2020

Address for correspondence:

mihageorgeta@yahoo.com
This work is licensed under a Creative Commons Attribution-NonCommercialNoDerivatives 4.0 International License

\begin{abstract}
Background and aims. The study describes the femoral (FN) and sciatic nerves (SN), explored using ultrasound (US) and magnetic resonance imaging (MRI). The aims of the study are: to establish US/MRI correlations and define reference values: for the anteroposterior (AP) and mediolateral (ML) diameters and cross-sectional area (CSA) of the two nerves respectively, in well-defined anatomical measuring sites; to analyze the intraobserver variation; to define the value with least variability; to determine differences between the right-left and male-female reference values.
\end{abstract}

Methods. A prospective study was carried out on 24 healthy volunteers (11 men and 13 women). MRI scans were performed using a $1.5 \mathrm{~T}$ system. To visualize both nerves (FN and $\mathrm{SN}$ ), a single 3D T2 weighted acquisition was performed, in the coronal plane, with a wide FOV. For ultrasonographic examinations, a Hitachi EUB8500 ultrasound machine, equipped with a $13 \mathrm{MHz}$ linear transducer was used. The measurements were performed at well-defined anatomical locations. The mean reference values of the AP, ML diameters and CSA were calculated for femoral and sciatic nerves, both on MRI and US. The correlations between the values determined by the two techniques were analyzed. The intra-observer variation was calculated by measuring the nerves at the same anatomical location at two separate time points.

Results. Wilcoxon matched-pairs signed rank test indicated a non-significant difference $(p>0.05)$ for the femoral and sciatic nerves, on both sides, except the femoral nerve ML diameter on MRI $(\mathrm{p}=0.014)$. The mean MRI and US reference values for the femoral nerve were calculated between the psoas and iliac muscles: FNAPMRI $4.533 \pm 0.486$, FNAPUS $4.800 \pm 1.237$, FNMLMRI $6.172 \pm 1.203$, FNMLUS $7.685 \pm 3.338$, FNCSAMRI $24.811 \pm 3.394$, FNCSAUS $26.285 \pm$ 17.608. The mean MRI and US measurements for the sciatic nerve were determined under the buttock, at the level of the ischial tuberosity: SNAPMRI $5.500 \pm 1.201$, SNAPUS $5.975 \pm 1.312$, SNMLMRI $10.375 \pm 2.272$, SNMLUS $13.500 \pm 1.661$, SNCSAMRI $50.625 \pm 15.373$, SNCSAUS $53.631 \pm 15.847$. The MRI and US differences between right and left sides, both for the femoral and sciatic nerves were insignificant. In selected cases, Wilcoxon paired test indicated differences between subjects, according to their gender, both on MRI and US.

Conclusion. Reference values for the femoral and sciatic nerves at specific anatomical sites were identified. Side to side variation and gender related differences add to current knowledge on nerve size in young Caucasian population.

Keywords: reference values, magnetic resonance imaging, ultrasonography, femoral nerve, sciatic nerve, observer variation 


\section{Background and aims}

Peripheral nerve imaging is mainly based on ultrasonography (US) and magnetic resonance imaging (MRI), which are non-invasive, complementary techniques. By using producer-defined presets for musculoskeletal exploration and high-frequency linear transducers [1], US allows real-time evaluation of the nerve path over long distances. The low cost, patient's comfort and the lack of contraindications are important advantages of the technique [2,3].

MRI, through the use of isotropic three-dimensional (3D) acquisitions, with high contrast resolution, allows the use of multiplanar reconstructed (MPR) images in complementary planes, for the accurate assessment of the nerves, which may be challenging with 2D imaging [4].

Although imaging is often used in the evaluation and quantification of neuropathies, there are few studies focused on establishing morphometric data, meant to complement the description of the normal appearance of the peripheral nerves [5-8].

The first objective of this study was to assess the feasibility of the two techniques as well as the correlation between the morphometric data provided by US and MRI in evaluating the femoral and sciatic nerves.

The second objective was to determine reference values for the cross-sectional area (CSA), the anteroposterior (AP) and mediolateral (ML) diameters of the two nerves. Male to female and left to right differences were also assessed.

An additional objective was to establish the intraobserver variability, estimated by using the ICC (Intraclass Correlation Coefficients) for one reader.

\section{Methods \\ Subjects}

The ethics committee of our institution approved the study and all subjects expressed their informed consent, regarding the image explorations.

A prospective study was conducted on 24 healthy volunteers, recruited from students and employees of the institution, over a four months period. The subjects did not report any history of peripheral neuropathy, diabetes or orthopedic interventions. We have defined three groups: MRI group (femoral nerve: $\mathrm{N}=15,8$ men, 7 women; sciatic nerve: $\mathrm{N}=13,7$ men, 6 women), US group (femoral nerve: $\mathrm{N}=16,7$ men, 9 women; sciatic nerve $\mathrm{N}=16,6$ men, 10 women) and MRI+US group (femoral and sciatic nerves: $\mathrm{N}=9,5$ men, 4 women). Age, height and weight were recorded and body mass index (BMI) was calculated for each subject.

\section{Imaging protocol}

US Protocol. A Hitachi EUB-8500 ultrasound machine equipped with a $5 \mathrm{~cm}$ footprint, $13 \mathrm{MHz}$ linear transducer was used. For the evaluation of the femoral nerve, the subjects were placed in supine position. An overview scan of the inguinal fossa was performed, identifying the inguinal ligament and external iliac vessels. The probe was moved cranially, approximately $3 \mathrm{~cm}$ above the inguinal ligament, where the femoral nerve was measured in the iliopsoas groove (Figure 1). This anatomical landmark was also used for the MRI assessment. Measurements were made just before the branching point, allowing for the maximum cross-sectional area to be recorded.

For the assessment of the sciatic nerve, the patients were placed in a prone position. The nerve was identified at the point of intersection with the gluteus maximus border (Figure 2). The exploration was performed bilaterally, using the same anatomical landmarks. For both nerves, the apparent nerve diameter was measured at the interface with the neighboring muscle structure.

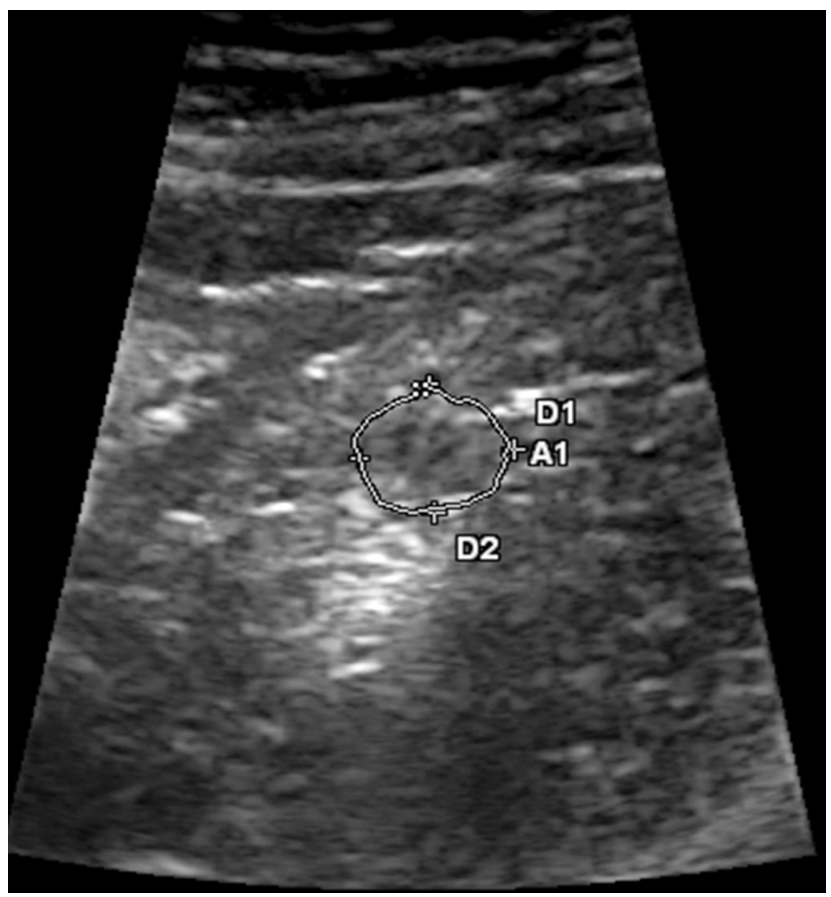

Figure 1. US measurement technique for the femoral nerve.

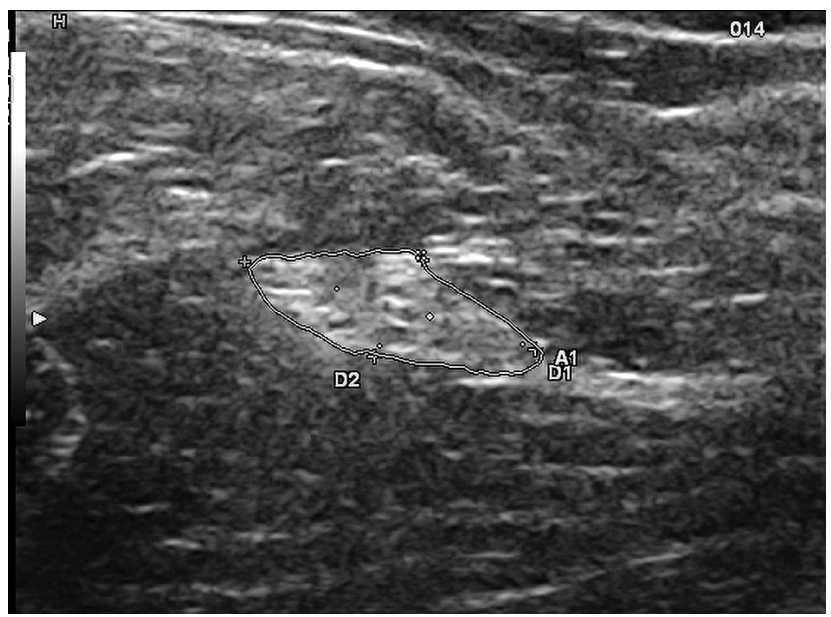

Figure 2. US measurement technique for the sciatic nerve. 
US measurement technique. For each nerve and each location, two perpendicular measurements of the transverse and anteroposterior diameter, between the apparent outer hyperechoic layer of the nerve, were performed. The focus was placed at the level of the nerve and the image was enlarged to remove irrelevant information.

MRI Protocol. The examinations were performed using a 1.5T GE Optima 360MR Advance 16-channel device. Two RF phased-array coils were positioned anteriorly and posteriorly relative to the subject. The subjects were placed in supine position. In order to obtain the best contrast between the nerves and the adjacent muscular tissues, a T2 weighted FSE sequence was chosen.
Isotropic 3D CUBE acquisition was used to obtain images with high spatial resolution. Acquisition parameters were: TR / TE $2500 \mathrm{~ms} / 151 \mathrm{~ms}$, ETL 100, Slice thickness 1.2 $\mathrm{mm}$, FOV $38 \mathrm{~cm}$, Matrix $320 \times 320$. The acquisition time was variable, depending on the planned slab size (7:30 $13 \mathrm{~min})$.

Image analysis. For the femoral nerve, the reference values were collected at the emergence between the psoas and iliac muscles, approximately at the level of the upper third of the S1 vertebra (Figure 3).

For the sciatic nerve, reference measurements were obtained at the level of ischial tuberosity, under the buttock (Figure 4).
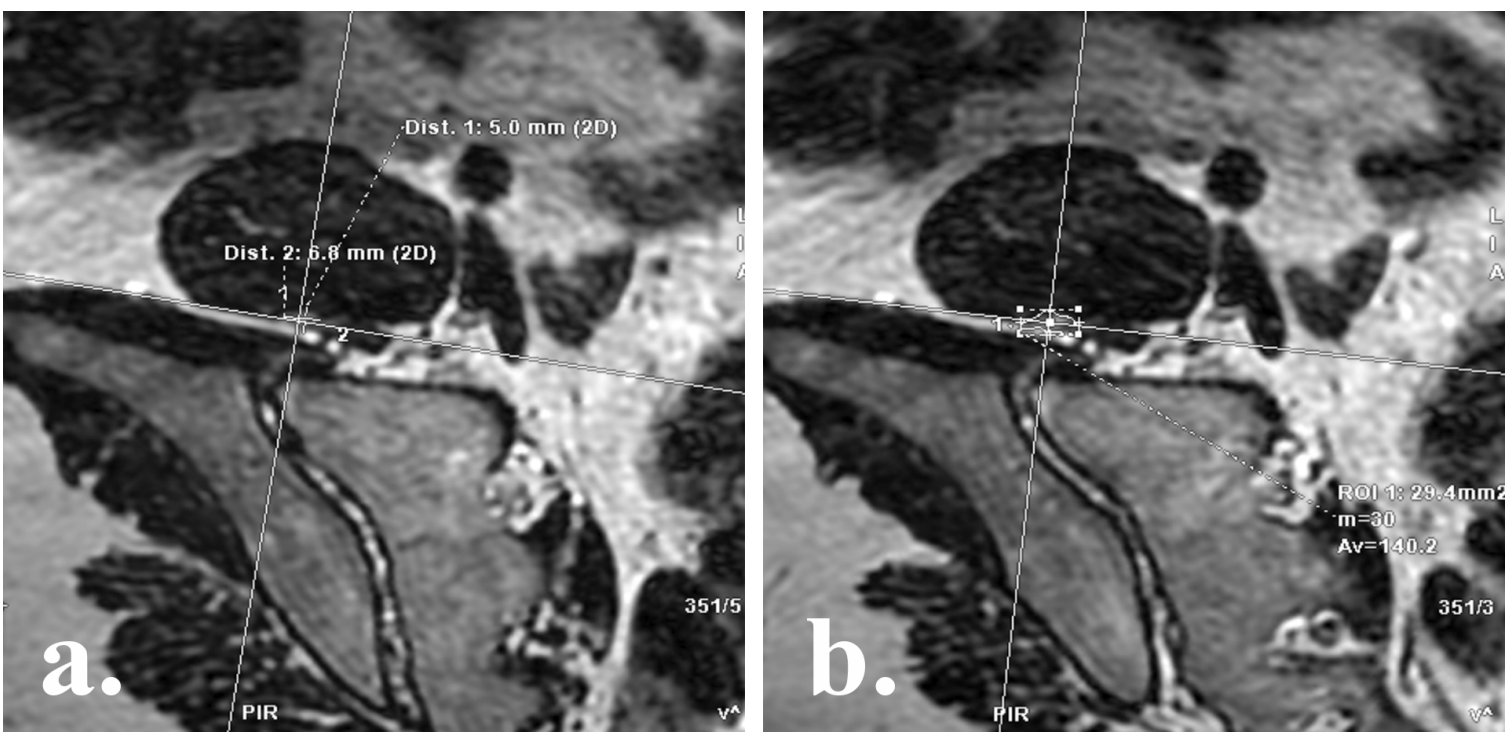

Figure 3. MRI measurement technique for the femoral nerve: a) AP and ML diameters; b) CSA.
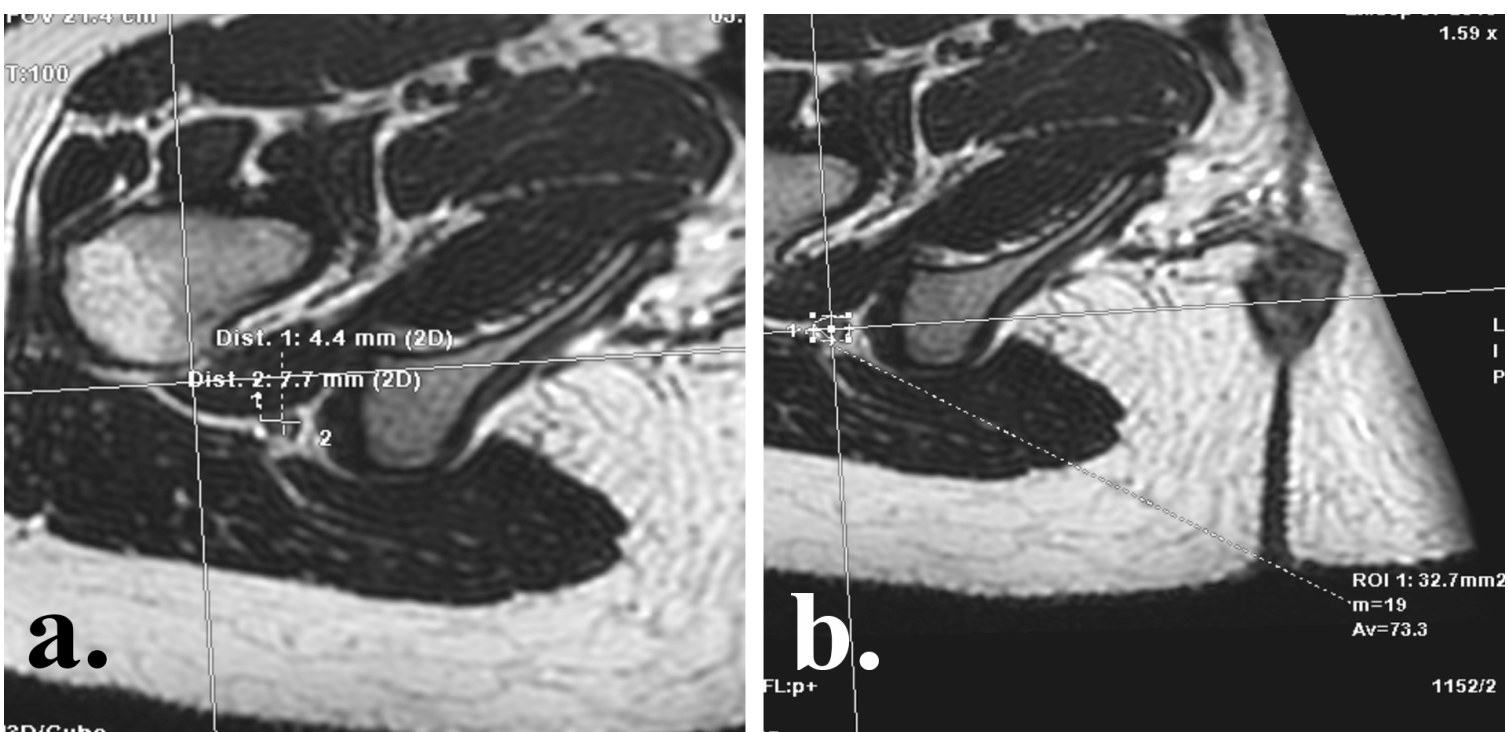

Figure 4. MRI measurement technique for the sciatic nerve: a) AP and ML diameters; b) CSA. 
MRI measurement technique. For post-processing, the images were imported into a GE 4.7 Advanced Workstation. Multiplanar reconstructions were performed and identification of nerve pathways was performed. Measurements of the AP, ML diameter and the crosssectional area were made in oblique axial planes, perpendicular to the nerve direction. After identifying the relevant axial section, the operator manually traced the AP and $\mathrm{ML}$ diameter and outlined the nerve circumference, obtaining the CSA.

\section{Statistical analysis}

Statistical analysis was performed using Statistical Package for Social Services (SPSS, IBM) version number 1.0.0.1327. For the subjects undergoing MRI examination, the reliability indicator was determined by calculating the ICC (Intraclass Correlation Coefficient) value. We considered it as poor ( $\mathrm{ICC}<0.5)$, moderate $(\mathrm{ICC}=0.50$ to 0.75), good ( $\mathrm{ICC}=0.75$ to 0.90 ) and excellent ( $\mathrm{ICC}>0.90)$, respectively. Wilcoxon Matched-Pairs Signed Ranks Test was used to assess intraobserver variability and side to side differences between the reference values. Applying the same test for each nerve, the differences between measured parameters on MRI vs. US were identified. Variation by gender for both MRI and US groups was estimated by using Mann-Whitney U Test. Spearman's rho coefficient was used to assess the correlation between the measured values and BMI.

\section{Results}

The study cohort consisted of 24 Caucasian subjects (mean age $24.29 \pm 2.555), 11$ men $(23.63 \pm 3.204)$ and 13 women $(25.17 \pm 0.98)$. Mean values \pm SD for femoral and sciatic nerves are presented in table I.

\section{Femoral Nerve}

Two measurements performed on MRI images were averaged and mean reference values \pm SD of reading 1 and reading 2 were used to analyze significance and intra-rater variability (ICC) (Table II). The analysis demonstrated insignificant differences for AP and ML diameters, both on right and left sides, between the two sets of measurements. For LFNCSA the difference was insignificant, while for RFNCSA the analysis showed a significant $\mathrm{p}$ value.

Table I. General descriptive statistics for the femoral and sciatic nerve data, measured on MRI and US.

\begin{tabular}{|c|c|c|}
\hline \multirow{2}{*}{ Ref. Value } & \multicolumn{2}{|c|}{ Mean Reference Value \pm SD } \\
\hline & MRI & US \\
\hline FNAP $(\mathrm{mm})$ & $4.533 \pm 0.486$ & $4.800 \pm 1.237$ \\
\hline FNML (mm) & $6.172 \pm 1.203$ & $7.685 \pm 3.338$ \\
\hline $\operatorname{FNCSA}\left(\mathrm{mm}^{2}\right)$ & $24.811 \pm 3.394$ & $26.285 \pm 17.608$ \\
\hline SNAP (mm) & $5.500 \pm 1.201$ & $5.975 \pm 1.312$ \\
\hline SNML (mm) & $10.375 \pm 2.272$ & $13.500 \pm 1.661$ \\
\hline $\operatorname{SNCSA}\left(\mathrm{mm}^{2}\right)$ & $50.625 \pm 15.373$ & $53.631 \pm 15.847$ \\
\hline
\end{tabular}

FNAP - femoral nerve anterior-posterior diameter, RFNNL - femoral nerve mediallateral diameter, RFNCSA - femoral nerve cross sectional area, SNAP - sciatic nerve anterior-posterior diameter, SNML - sciatic nerve medial-lateral diameter, SNCSA sciatic nerve cross sectional area, SD - standard deviation.

Table II. Intraobserver variability and ICC for the two sets of MRI measurements involving femoral and sciatic nerves.

\begin{tabular}{|c|c|c|c|c|c|}
\hline Ref. Value & Side & $\begin{array}{c}\text { Reading } 1 \\
\text { Mean } \pm \text { SD }\end{array}$ & $\begin{array}{c}\text { Reading } 2 \\
\text { Mean } \pm \text { SD }\end{array}$ & p value & ICC \\
\hline FNAP (mm) & \multirow{3}{*}{ right } & $4.300 \pm 0.900$ & $4.526 \pm 0.742$ & 0.146 & 0.680 \\
\hline FNML (mm) & & $5.880 \pm 1.056$ & $6.040 \pm 0.920$ & 0.820 & 0.487 \\
\hline FNCSA $\left(\mathrm{mm}^{2}\right)$ & & $23.800 \pm 6.377$ & $26.060 \pm 5.190$ & 0.026 & 0.766 \\
\hline FNAP (mm) & \multirow{3}{*}{ left } & $4.080 \pm 0.922$ & $4.313 \pm 0.793$ & 0.139 & 0.611 \\
\hline FNML (mm) & & $6.506 \pm 1.152$ & $6.526 \pm 1.162$ & 0.909 & 0.711 \\
\hline FNCSA $\left(\mathrm{mm}^{2}\right)$ & & $24.766 \pm 6.452$ & $26.200 \pm 6.663$ & 0.112 & 0.866 \\
\hline SNAP (mm) & \multirow{3}{*}{ right } & $6.369 \pm 1.500$ & $6.023 \pm 1.278$ & 0.362 & 0.778 \\
\hline SNML (mm) & & $10.346 \pm 2.450$ & $10.700 \pm 3.090$ & 0.780 & 0.742 \\
\hline $\operatorname{SNCSA}\left(\mathbf{m m}^{2}\right)$ & & $54.400 \pm 23.153$ & $59.269 \pm 23.126$ & 0.028 & 0.943 \\
\hline SNAP (mm) & \multirow{3}{*}{ left } & $5.615 \pm 1.669$ & $5.969 \pm 1.629$ & 0.195 & 0.876 \\
\hline SNML (mm) & & $10.538 \pm 1.678$ & $10.946 \pm 1.812$ & 0.363 & 0.745 \\
\hline $\operatorname{SNCSA}\left(\mathrm{mm}^{2}\right)$ & & $59.707 \pm 20.067$ & $62.792 \pm 22.485$ & 0.311 & 0.856 \\
\hline
\end{tabular}


Side to side paired difference test, applied for all the subjects from the MRI group ( $\mathrm{N}=30$ samples totally) indicated an insignificant difference for FNAP diameter $(p=0.318)$, FNCSA $(p=0.631)$ calculated variances and a significant difference for FNML diameter $(\mathrm{p}=0.014)$ respectively. On US, Wilcoxon test revealed that means were not significantly different for all determined parameters (FNAP $\mathrm{p}=0.821$, FNML $\mathrm{p}=0.087$, FNCSA $\mathrm{p}=0.736$ ).

Regarding gender differences, the number of measurements on MRI examinations aggregated all values collected from reads 1 and 2 ( $\mathrm{N}=30$ samples). On the right side, the difference between the two genders was insignificant in terms of AP diameter and significant for ML diameter and CSA. On the left side, the difference between men and women was also significant for all the measured values. The general calculation (right + left sides, performed on $\mathrm{N}=60$ samples) showed a significant difference $(\mathrm{p}=0.001)$ between men and women, for all three studied variables (Table III).

For the US explored group, the difference between men and women was insignificant for AP, ML diameters and CSA, both on right and left side. The aggregate calculation (right + left, performed on $\mathrm{N}=12$ samples for men and $\mathrm{N}=20$ samples for women) reported insignificant differences for all studied parameters (Table III).

Regarding the MRI-US group consisting of 9 subjects (5 men, 4 women), 18 samples (right + left), there were similarities among the pairs of values obtained by the two imaging techniques: FNAPMRI - FNAPUS $(p=0.338)$, FNMLMRI-FNMLUS ( $p=0.126$ ), FNCSAMRI-FNCSAUS $(\mathrm{p}=0.652)$. Moreover, on the same group, Mann-Whitney U test revealed insignificant differences between men and women for all the parameters: FNAPMRI ( $\mathrm{p}=0.398)$, FNAPUS $(\mathrm{p}=0.698)$, FNMLMRI $(p=0.070)$, FNMLUS $(p=0.796)$, FNCSAMRI $(\mathrm{p}=0.093)$, FNCSAUS $(\mathrm{p}=1)$.

The correlation between reference values and BMI for the femoral nerve, calculated on MRI group, was weak for FNAP (Spearman rho 0.195, $\mathrm{p}=0.136$ ) and FNCSA (Spearman rho 0.263, $\mathrm{p}=0.042$ ) and very low for FNML (Spearman rho 0.027, $\mathrm{p}=0.838$ ). In US explored group, the obtained correlation was moderate for FNAP (Spearman rho 0.416, $\mathrm{p}=0.020$ ) and FNML (Spearman rho 0.408, $\mathrm{p}=0.023$ ) and strong for CSA (Spearman rho 0.530, $\mathrm{p}=0.002$ ) respectively.

\section{Sciatic Nerve}

Intraobserver variability of measurements indicated concordance between reads 1 and 2 for all parameters, except for the right sciatic nerve CSA $(\mathrm{p}=0.04)$. Likewise, intrareader agreement was moderate to good and excellent for all measured parameters (Table II).

The Wilcoxon test results obtained in side to side pairs, applied to MRI group data, indicated there was an insignificant difference for all parameters (LSNAPRSNAP $p=0.242$, LSNML-RSNML $p=0.703$, LSNCSARSNCSA $\mathrm{p}=0.258$ ), aspect also found in the statistical calculations that targeted the US group (LSNAP-RSNAP $p=0.258$, LSNML-RSNML $p=0.918$, LSNCSA-RSNCSA $\mathrm{p}=0.198)$.

Depending on gender, measurements for the MRI group cumulated data collected from both readings (totally $\mathrm{N}=26$ samples, $\mathrm{N}=14$ for men). Both on the right and the left side, the Mann-Whitney test revealed significant differences between the two genders, in terms of RSNCSA ( $p=0.039)$ and LSNCSA $(p=0.010)$. The general calculation (right + left) indicated significant men-women differences for all determined parameters (SNAP $\mathrm{p}=0.013, \mathrm{SNML} \mathrm{p}=0.015$ and SNCSA $\mathrm{p}=0.001)$ (Table IV).

Table III. Descriptive group statistics for the femoral nerve MRI and US measurements according to gender.

\begin{tabular}{ll|c|c|c|c|c|c}
\multirow{2}{*}{$\begin{array}{l}\text { Ref. } \\
\text { Value }\end{array}$} & \multirow{2}{*}{ Gender } & \multicolumn{2}{|c|}{ MRI Mean Reference Value \pm SD } & \multicolumn{2}{c}{ US Mean reference value \pm SD } \\
\cline { 3 - 8 } & & Right & Left & $\begin{array}{c}\text { General } \\
\text { (right+left) }\end{array}$ & Right & Left & $5.133 \pm 0.575$ \\
(right+left)
\end{tabular}

Table IV. Descriptive group statistics for the sciatic nerve MRI and US measurements according to gender.

\begin{tabular}{|c|c|c|c|c|c|c|c|}
\hline \multirow{2}{*}{$\begin{array}{l}\text { Ref. } \\
\text { Value }\end{array}$} & \multirow[b]{2}{*}{ Gender } & \multicolumn{3}{|c|}{ MRI Mean Reference Value \pm SD } & \multicolumn{3}{|c|}{ US Mean reference value \pm SD } \\
\hline & & Right & Left & $\begin{array}{c}\text { General } \\
\text { (right+left) }\end{array}$ & Right & Left & $\begin{array}{c}\text { General } \\
\text { (right+left) }\end{array}$ \\
\hline & & & & $6.532 \pm 1.510$ & & & $6.900 \pm 2.035$ \\
\hline & & 0 & 5.125 & $5.366 \pm$ & 5.88 & 6.077 & 5.983 \\
\hline & & $\begin{array}{c}11.642 \pm 2.343 \\
9.216 \pm 2.663\end{array}$ & & $\begin{array}{c}11.425 \pm 1.951 \\
9.708 \pm 2.298\end{array}$ & $\begin{array}{l}12.342 \pm 4.273 \\
11.444 \pm 2.188\end{array}$ & $\begin{array}{c}13.357 \pm \\
9.944 \pm\end{array}$ & $\begin{array}{l}12.850 \pm 4.352 \\
10.694 \pm 3.131\end{array}$ \\
\hline & $\begin{array}{l}\text { ale } \\
\text { emale }\end{array}$ & $\begin{array}{l}69.321 \pm 22.725 \\
42.266 \pm 11.913\end{array}$ & $\begin{array}{c}71.492 \pm 22.727 \\
49.300 \pm 9.834\end{array}$ & $\begin{array}{l}70.407 \pm 22.329 \\
45.783 \pm 11.271\end{array}$ & $\begin{array}{l}59.000 \pm 15.758 \\
43.111 \pm 11.318\end{array}$ & $\begin{array}{l}71.000 \pm 25.449 \\
41.111 \pm 14.768\end{array}$ & $\begin{array}{l}65.000 \pm 21.267 \\
42.111 \pm 12.805\end{array}$ \\
\hline
\end{tabular}


The same test applied on the US explored group highlighted a significant difference for CSA values on both sides (RSNCSA $p=0.039$, LSNCSA $p=0.010$ ). The general calculation (right + left, performed on $\mathrm{N}=12$ samples for men and $\mathrm{N}=20$ samples for women) indicated that men had thicker sciatic nerves compared to women (SNCSA p $=0.001)$ (Table IV).

Data differences between the two imaging techniques were determined on MRI-US group. Wilcoxon analysis revealed an analogy of measurements for all parameters, except the mediolateral diameter of sciatic nerve $(p=0.001)$. Differences among genders mean reference values were insignificant for the following parameters: SNAPMRI $(\mathrm{p}=0.532), \quad$ SNMLMRI $(\mathrm{p}=0.2014)$, SNAPUS $(\mathrm{p}=0.524)$, SNMLUS $(\mathrm{p}=0.599)$, SNCSAUS $(p=0.248)$ and statistically significant for SNCSAMRI $(\mathrm{p}=0.016)$.

On MRI examined group, the correlation of nerve reference values with BMI was weak for all parameters: SNAP (Spearman rho 0.158, $\mathrm{p}=0.263$ ), SNML (Spearman rho -0.012, $\mathrm{p}=0.933$ ), SNCSA (Spearman rho 0.120, $\mathrm{p}=0.396$ ). Tests for sciatic nerve on US explored group showed a moderate correlation for SNAP (Spearman rho 0.302, $\mathrm{p}=0.093$ ), very weak for SNML (Spearman rho $0.064, p=0.337$ ) and weak for SNCSA (Spearman rho $0.176, \mathrm{p}=0.337)$.

\section{Discussion}

The primary objective of this study was to obtain morphometric information targeting the femoral and sciatic nerves, using data obtained through HRUS and MRI, at precise landmarks, in healthy Caucasian subjects of young age. Previous ultrasound studies carried out on volunteers of different ages, provided information about different peripheral nerve CSA, according to race characteristics [9-12]. In our study, no significant differences were seen between the US and MRI groups. All the reference values obtained for the femoral and sciatic nerves were comparable, indicating accuracy of the two complementary imaging techniques.

There are only a few published studies that compared data obtained by the two imaging techniques for several nerves of the brachial and lumbosacral plexus, upper and lower limb, generally in pathological context, establishing a variable correlation (fair to excellent) between the techniques [13-17]. Some authors published measurements of nerve CSA by MRI and HRUS, establishing strong correlations between the obtained data $[14,15]$.

Most previous studies $[9,11,12,18]$ focused exclusively on HRUS, determining CSA values. The technique was considered safe, inexpensive, non-invasive, fast and dynamic [19], the first intention in the evaluation of peripheral nerve pathology [20].

On the other hand, MRI is not operator-dependent and is useful in detecting pathological aspects [19,20] with high sensitivity in assessing peripheral nerves using $\mathrm{T} 2$ weighted sequences [17]. In our study, in the same 3D morphological acquisition, performed in the coronal plane with high FOV, we obtained images of both the femoral and sciatic nerves, contributing to the reduction of the impediments related to the acquisition time. Subsequently, the data were reconstructed, the diameters and sectional areas being accurately measured in planes perpendicular to the nerve path.

Within the MRI-explored group, the results of the ICC values indicated a moderate, good and excellent reliability, demonstrating the reproducibility of the measurements and the MRI reliability in determining the reference values for the two studied nerves. From this point of view, a similar result (intrareader consistency 0.990 for the lumbosacral plexus) was obtained in another study, performed exclusively with MRI on a large number of subjects, which targeted multimodal measurements at the level of the brachial and lumbosacral plexus [21].

Side to side analysis indicated similarities between right and left measured parameters, both in the USexplored group and the MRI-explored group, except for the size of the mediolateral diameter of the femoral nerve, determined on MRI. These differences may be due to anatomical features: the oval or triangular appearance, with an impact on the mediolateral dimension, the content of fascicular structures and the epineural and perineural fatty tissue. It may also be attributed to the small number of subjects in the analyzed group, but also to the topographic position, respectively the measurement site, located, in our case, immediately under the emergence of the roots of the lumbar plexus, between the iliac muscle and the lateral face of the psoas. A previous study indicated slight increase in size of the femoral nerve from proximal to distal, both in volunteers and in the patient group [18]. Also, some authors mentioned different levels of measurement of the femoral nerve size, in lacuna musculorum [22] either above or below the groin ligament [18]. However, data on the anteroposterior diameter and CSA of the femoral nerve coincided with those in the literature, regardless of the acquisition technique.

For the sciatic nerve, our data did not show rightleft differences, at the level of measurement defined by us, in either the MRI or US groups. This information converses with previously published studies with measurements performed at about the same level [23]. Others have established different measurement sites: at the level of the piriformis muscle [22] or below it [5], midthigh on the dorsal face [23-25] or before the bifurcation [22]. Our data confirmed the side-to-side symmetry of the CSA, useful in the context of characterizing the size changes that occur in various asymmetric disorders of the peripheral nerves $[26,27]$. 
Table V. MRI-measured mediolateral mean diameter of the femoral and sciatic nerves.

\begin{tabular}{l|c|c|c|c|}
\multirow{2}{*}{ Nerve / side } & \multicolumn{2}{|c|}{ Cho Sims et al. [5] } & \multicolumn{2}{c|}{ Present study } \\
\cline { 2 - 5 } & $\begin{array}{c}\text { Reader 1 } \\
\text { Mean } \pm \text { SD }\end{array}$ & $\begin{array}{c}\text { Reader 2 } \\
\text { Mean } \pm \text { SD }\end{array}$ & $\begin{array}{c}\text { Reading 1 } \\
\text { Mean } \pm \text { SD }\end{array}$ & $\begin{array}{c}\text { Reading 2 } \\
\text { Mean } \pm \text { SD }\end{array}$ \\
\hline Femoral / right & $4.52 \pm 1.11$ & $4.85 \pm 0.64$ & $5.88 \pm 1.05$ & $6.04 \pm 0.92$ \\
Femoral / left & $4.48 \pm 0.97$ & $4.94 \pm 0.57$ & $6.50 \pm 1.15$ & $6.52 \pm 1.16$ \\
Sciatic / right & $9.71 \pm 1.76$ & $9.94 \pm 0.83$ & $10.34 \pm 2.45$ & $10.70 \pm 3.09$ \\
Sciatic / left & $10.03 \pm 1.71$ & $9.98 \pm 0.99$ & $10.53 \pm 1.67$ & $10.94 \pm 1.81$
\end{tabular}

In the MRI group, a significant difference between women and men was recorded for all parameters measured on the right, left, and general (right + left), both for the sciatic nerve and for the femoral nerve, in the sense that the dimensions measured in men were larger than those measured in women. In the US group, this relationship was confirmed only for the CSA value, following the same statistical evaluation criteria as for the MRI data. This observation confirmed the data published by previous studies regarding the gender difference of the cross-sectional area, determined both with ultrasound $[23,24,28]$ and MRI [21].

Our study revealed a low correlation between CSA and BMI, except the data obtained for the femoral nerve in the US group. In the literature, there are controversies regarding the relation between the two parameters. In a recent study based on MRI measurements on the same nerves, no correlations were found between the mediolateral diameter and BMI [21], a finding supported by other previous studies focusing on ultrasonographic measurements [24,28].

Nevertheless, other authors mentioned the correlation between CSA and BMI for the sciatic nerve $[10,22]$. On the aggregate, more studies reported a correlation between BMI and size for different nerves of the upper and lower limbs $[9,11,12,23]$. In a recent study published by our group, focused on three nerves of the cervical region, we found a significant correlation for a particular one [29]. Both the differences between ultrasound and MRI measurements and the variable relationship with BMI may be explained by the measurement technique. In US, the apparent diameter of the nerve, marked by the boundary with neighboring muscle structures, is measured. This measurement also includes epineurium, connective tissue having signal similar to adipose tissue. In patients with high BMI, the intermuscular adipose plane is better represented and is probably included in the measurements.

To the best of our knowledge, this study is the first to compare US and MRI measurements of peripheral nerves performed on the same set of volunteers. It is observed that both the average values measured by the US and their standard deviation are marginally higher than in MRI for all the parameters of femoral and sciatic nerves but statistically different only for the mediolateral diameter of the sciatic nerve. One possible explanation of this observation is the US measurement technique, as described above. The femoral nerve was measured at different levels on US and MRI. The location chosen for the US measurement (location 1) allows for a reliable identification of the nerve trunk just before the branching point. The area chosen for the MR measurement (location 2) is situated, anatomically, approximately $5 \mathrm{~cm}$ higher up. At this location, the nerve can be readily identified and measured. MRI cannot identify the nerve in location 1 while the same nerve is inaccessible on US in location 2. We considered this compromise to be acceptable, as between the two points there is, basically, no branching of the nerve, with only 2-3 tiny iliacus muscle lateral branches emerging.

On MRI, the mediolateral diameters of the femoral and sciatic nerves, measured in the current study, were comparable to the ones reported in a previous study [5], as presented in table $\mathrm{V}$.

Marginal differences between the mean mediolateral diameter determined values may be due to the different proportion between men and women in the two studies (1:3.72 in the previous study; 1.14:1 in this study).

The limitations of this study should also be considered. The small number of subjects studied, as a result of strict inclusion criteria in a limited time window, makes the observations applicable only to young and healthy Caucasian persons.

The influence of the differences between the sampling sites of the measurements, inherent for the two methods, was mitigated as much as possible by the technique of identification and measurement, but it cannot be overlooked.

Further studies on a larger scale are necessary to establish baseline values of the dimensions of peripheral nerves not only according to gender and location, but also by age groups.

\section{Conclusion}

In clinical practice, the main abnormal aspects involving peripheral nerves are related to changes in size and structure. Thus, to quantify this information, a set of normal reference values are required. Our study demonstrated a good intraobserver reproducibility of MRI measurement of the studied nerves. The values measured by US and their standard deviation are higher than in the case of MR. In young Caucasian patients the size of the nerves depends on the gender, being larger in men. Normal values of nerve dimensions were established for the studied groups. Further studies are needed to define normal values according to different age groups. 


\section{References}

1. Ohana M, Moser T, Moussaouï A, Kremer S, Carlier RY, Liverneaux $\mathrm{P}$, et al. Current and future imaging of the peripheral nervous system. Diagn Interv Imaging. 2014;95:17-26.

2. Jacobson JA, Wilson TJ, Yang LJ. Sonography of Common Peripheral Nerve Disorders With Clinical Correlation. J Ultrasound Med. 2016;35:683-693.

3. Ali ZS, Pisapia JM, Ma TS, Zager EL, Heuer GG, Khoury V. Ultrasonographic Evaluation of Peripheral Nerves. World Neurosurg. 2016;85:333-339.

4. Ahlawat S, Carrino JA. Three-dimensional imaging of lower limb neuropathies. Semin Musculoskelet Radiol. 2015;19:168178.

5. Cho Sims G, Boothe E, Joodi R, Chhabra A. 3D MR Neurography of the Lumbosacral Plexus: Obtaining Optimal Images for Selective Longitudinal Nerve Depiction. AJNR Am J Neuroradiol. 2016;37:2158-2162.

6. Prameela MD, Rajalakshmi RAI. Anatomical study of width and thickness of sciatic nerve in the gluteal region. In: Proceedings of 2nd ISERD International Conference, Dubai, UAE, 23rd May 2015. Available from: http://www. worldresearchlibrary.org/up_proc/pdf/31-143229076226-28. pdf.

7. Oyedun OS, Rukewe A, Fatiregun A. Femoral nerve dimensions at the inguinal ligament and inguinal crease levels: implications for femoral nerve block. J Morphol Sci. 2014;31:207-209.

8. Gruber H, Peer S, Kovacs P, Marth R, Bodner G. The ultrasonographic appearance of the femoral nerve and cases of iatrogenic impairment. J Ultrasound Med. 2003;22:163-172.

9. Cartwright MS, Mayans DR, Gillson NA, Griffin LP, Walker FO. Nerve cross-sectional area in extremes of age. Muscle Nerve. 2013;47:890-893.

10. Seok HY, Jang JH, Won SJ, Yoon JS, Park KS, Kim BJ. Cross-sectional area reference values of nerves in the lower extremities using ultrasonography. Muscle Nerve. 2014;50:564-570.

11. Qrimli M, Ebadi H, Breiner A, Siddiqui H, Alabdali M, Abraham A, et al. Reference values for ultrasonograpy of peripheral nerves. Muscle Nerve. 2016;53:538-544.

12. Bedewi MA, Abodonya A, Kotb M, Kamal S, Mahmoud G, Aldossari A, et al. Estimation of ultrasound reference values for the lower limb peripheral nerves in adults: A crosssectional study. Medicine (Baltimore). 2018;97:e0179.

13. Zaidman CM, Seelig MJ, Baker JC, Mackinnon SE, Pestronk A. Detection of peripheral nerve pathology: comparison of ultrasound and MRI. Neurology. 2013;80:1634-1640.

14. Jongbloed BA, Haakma W, Goedee HS, Bos JW, Bos C, Hendrikse J, et al. Comparative study of peripheral nerve Mri and ultrasound in multifocal motor neuropathy and amyotrophic lateral sclerosis. Muscle Nerve. 2016;54:11331135.

15. Pitarokoili K, Kronlage M, Bäumer P, Schwarz D, Gold $\mathrm{R}$, Bendszus $\mathrm{M}$, et al. High-resolution nerve ultrasound and magnetic resonance neurography as complementary neuroimaging tools for chronic inflammatory demyelinating polyneuropathy. Ther Adv Neurol Disord. 2018;11:1756286418759974.

16. Agarwal A, Chandra A, Jaipal U, Bagarhatta M, Mendiratta $\mathrm{K}$, Goyal A et al. Can imaging be the new yardstick for diagnosing peripheral neuropathy?-A comparison between high resolution ultrasound and MR neurography with an approach to diagnosis. Insights Imaging. 2019;10:104.

17. Aggarwal A, Srivastava DN, Jana M, Sharma R, Gamanagatti S, Kumar A, et al. Comparison of Different Sequences of Magnetic Resonance Imaging and Ultrasonography with Nerve Conduction Studies in Peripheral Neuropathies. World Neurosurg. 2017;108:185-200.

18. Gruber H, Peer S, Kovacs P, Marth R, Bodner G. The ultrasonographic appearance of the femoral nerve and cases of iatrogenic impairment. J Ultrasound Med. 2003;22:163-172.

19. Beekman R, Visser LH. High-resolution sonography of the peripheral nervous system -- a review of the literature. Eur J Neurol. 2004;11:305-314.

20. Padua L, Hobson-Webb LD. Ultrasound as the first choice for peripheral nerve imaging? Neurology. 2013;80:1626-1627.

21. Su X, Kong X, Liu D, Kong X, Alwalid O, Wang J, et al. Multimodal magnetic resonance imaging of peripheral nerves: Establishment and validation of brachial and lumbosacral plexi measurements in 163 healthy subjects. Eur J Radiol. 2019;117:41-48

22. Tagliafico A, Cadoni A, Fisci E, Bignotti B, Padua L, Martinoli C. Reliability of side-to-side ultrasound cross-sectional area measurements of lower extremity nerves in healthy subjects. Muscle Nerve. 2012;46:717-722.

23. Chen J, Liu J, Zeng J, Wu S, Ren J. Ultrasonographic Reference Values for Assessing Normal Sciatic Nerve Ultrasonography in the Normal Population. J Med Ultrasound. 2018;26:85-89.

24. Heinemeyer $\mathrm{O}$, Reimers $\mathrm{CD}$. Ultrasound of radial, ulnar, median, and sciatic nerves in healthy subjects and patients with hereditary motor and sensory neuropathies. Ultrasound Med Biol. 1999;25:481-485.

25. Tiftik T, Öztürk GT, Kara M, Türkkan C, Ersöz M, Özçakar L. Ultrasonographic evaluation of sciatic nerves in patients with spinal cord injury. Spinal Cord. 2015;53:75-77.

26. Uğurlu FG, Tiftik T, Kara M, Türkkan C, Ersöz M, Akkuş S, et al. Ultrasonographic evaluation of the median and sciatic nerves in hemiplegic patients after stroke. Am J Phys Med Rehabil. 2015;94:429-435.

27. Sinclair CD, Miranda MA, Cowley P, Morrow JM, Davagnanam I, Mehta H, et al. MRI shows increased sciatic nerve cross sectional area in inherited and inflammatory neuropathies. J Neurol Neurosurg Psychiatry. 2011;82:12831286.

28. Boehm J, Scheidl E, Bereczki D, Schelle T, Arányi Z. Highresolution ultrasonography of peripheral nerves: measurements on 14 nerve segments in 56 healthy subjects and reliability assessments. Ultraschall Med. 2014;35:459-467.

29. Curcean AD, Rusu MG, Dudea SM. Ultrasound appearance of peripheral nerves in the neck: vagus, hypoglossal and greater auricular. Med Pharm Rep. 2020;93:39-46. 